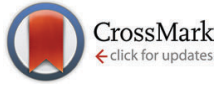

Cite this: J. Mater. Chem. C, 2015 , 3, 12430

Received 29th September 2015, Accepted 9th November 2015

DOI: $10.1039 / c 5 t c 03107 a$

www.rsc.org/MaterialsC

\title{
Air bubble promoted large scale synthesis of luminescent $\mathrm{ZnO}$ nanoparticles
}

\author{
S. Koch, ${ }^{\text {ab }}$ S. Späth, ${ }^{c}$ A. Shmeliov, ${ }^{d}$ V. Nicolosi ${ }^{d}$ and K. Mandel ${ }^{\star a c}$
}

Luminescent zinc oxide nanoparticles were synthesized via a facile one-pot sol-gel synthesis route using zinc acetate dihydrate and potassium hydroxide as cheap precursors. It is demonstrated that dissolved oxygen plays a key role in the synthesis of nanoparticles. For larger scale synthesis batches, it is therefore crucial to provide sufficient oxygen supply during reaction, as otherwise, the formation of $\mathrm{ZnO}$ nanoparticles does not occur. A concept is presented to achieve a large gas to liquid interface by introducing air bubbles into the reaction system to ultimately promote $\mathrm{ZnO}$ nanoparticle formation at larger scale batches. The flow rate of air during synthesis directly influences the yield and the luminescence intensity of the nanoparticles.

\section{Introduction}

Zinc oxide nanostructures arise increasing interest due to their versatile applicability in advanced materials applications for instance in the fields of electronics, optoelectronics, piezoelectronics or spintronics. ${ }^{1,2}$ Furthermore nano-ZnO is, beyond UV-protection in sun-creams, an interesting material for applications directly linked to the human body, such as medical products or bio-imaging., ${ }^{3,4}$ The broad applicability arises from the extraordinary electronic, magnetic and optical properties of this semiconductor nanomaterial, mainly due to the quantum confinement effects and the defect-rich wurtzite crystal structure. ${ }^{1,3,5}$

$\mathrm{ZnO}$ is a direct and wide band gap material $(3.4 \mathrm{eV})$ showing a narrow exitonic near band edge emission $(\sim 380 \mathrm{~nm}) .{ }^{6}$ Therefore, it is a very promising material for UV light-emitting optoelectronic devices including light-emitting diodes or laser diodes. ${ }^{2,5}$ Particularly interesting is that undoped $\mathrm{ZnO}$ quantum dots may also exhibit photoluminescence in the visible wavelength range. The origin of this light emission is mainly attributed to the presence of oxygen vacancies in the crystal structure of $\mathrm{ZnO}$ nanoparticles. ${ }^{6-9}$ The visible emission is supposed to be caused by electron transitions from the conduction band to a deep-level hole defect. ${ }^{10,11}$ These deep-level defects were identified as doubly charged oxygen vacancies originating from the charging of an oxygen vacancy with a photogenerated hole. To ensure the

\footnotetext{
${ }^{a}$ Fraunhofer Institute for Silicate Research, ISC, Neunerplatz 2, 97082 Würzburg, Germany. E-mail: karl-sebastian.mandel@isc.fraunhofer.de

${ }^{b}$ University Bordeaux, Institute of Science Moléculaire, UMR-5255,

351 cours de la Libération, 33405 Talence, France

${ }^{c}$ University Würzburg, Chair of Chemical Technology of Materials Synthesis,

Röntgenring 11, 97070 Würzburg, Germany

${ }^{d}$ Trinity College Dublin, Advanced Microscopy Laboratory,

Unit 27-29 Grand Canal Quay D02, DA31 Dublin, Ireland
}

formation of these defects, adsorbed surface groups, scavenging the photoexcited electrons, have to be present. These might be bridging acetates, oxygen or hydroxyl groups. ${ }^{7,11}$ Therefore, the visible luminescence of $\mathrm{ZnO}$ quantum dots also depends on the synthesis method as this influences for example the nanoparticle surface character, crystallinity and purity. ${ }^{10}$ For small particles, due to quantum confinement, the width of the bandgap and therefore also the difference between the conduction band and defect states increases. ${ }^{12}$ Consequently, the emitted (visible) colors that depend on that width are directly related to the nanoparticle size. ${ }^{10,11}$ Due to their adjustable color emission, these (non-toxic, heavy-metal-replacing) undoped ZnO quantum dots can be of particular interest for a number of applications such as high-quality imaging of ZnO labelled cells, light-emitting diodes, sensors with optical read out or anti-fake labelling. ${ }^{13-16}$

Various synthesis approaches have been developed in the last few decades to fabricate $\mathrm{ZnO}$ nanostructures with quantum confined properties. These can be divided into chemical methods like precipitation, ${ }^{17,18}$ sol-gel reactions ${ }^{19,20}$ and hydrothermal treatment ${ }^{21,22}$ and into physical methods, e.g. vapor $^{23,24}$ or pulsed laser ${ }^{25,26}$ deposition. While chemical methods can often be considered as low cost synthetic routes suitable for upscaling, physical methods result in highly crystallized particles with high purity and fine UV emission. ${ }^{24,26}$ If visible light-emitting undoped $\mathrm{ZnO}$ quantum dots shall be obtained, synthesis routes causing high defect densities, i.e. a lot of oxygen vacancies within the crystal, are needed. This can be achieved for instance via decomposition of organo-zinc derivatives, ${ }^{27}$ electrolysis, ${ }^{16}$ hydrothermal treatment ${ }^{28}$ or sol-gel techniques. The sol-gel synthesis is most often chosen to obtain $\mathrm{ZnO}$ nanoparticles with highly visible emission intensities as in contrast to the other methods, it shows advantages like process simplicity, high homogeneity and the preparation of particles at low cost and low temperature. ${ }^{29,30}$ 
The most common sol-gel synthesis uses zinc acetate precursors and a base such as $\mathrm{KOH}$ or $\mathrm{LiOH}$ in alcohol as the solvent. ${ }^{20,31-33}$ Recent studies reported on a simplified method that made any heating and refluxing of the zinc acetate precursor unnecessary. The base and zinc acetate are just separately dissolved in ethanol and are then combined and stirred for the required time at room temperature. ${ }^{10,14}$ However, with this synthesis approach, only small batches can be realized and the achieved concentration of nanoparticles is rather low. A precondition for bringing these well-defined $\mathrm{ZnO}$ nanoparticles in dispersion towards application is the capability to synthesize substantial quantities with comparable ease. Only then, prototype materials for application can be created and the performance of these $\mathrm{ZnO}$ nanoparticles can be compared to other materials such as gas-phase synthesized ZnO. The demonstration of upscalability and the increase of product yield are therefore essential. We found that a key towards this is to add air-bubbles to the synthesis. By doing so, with this novel approach, it is possible to produce substantial amounts of well-defined nano-ZnO in an easy and inexpensive way.

\section{Experimental methods}

\section{Materials}

Zinc acetate dihydrate $\left(\mathrm{Zn}\left(\mathrm{CH}_{3} \mathrm{CO}_{2}\right)_{2} \cdot 2 \mathrm{H}_{2} \mathrm{O}\right)$, zinc acetate $(99.9 \%$, $\left.\mathrm{Zn}\left(\mathrm{CH}_{3} \mathrm{CO}_{2}\right)_{2}\right)$, lithium hydroxide $(98 \%, \mathrm{LiOH})$, potassium hydroxide flakes $(90 \%, \mathrm{KOH})$ and ethanol were purchased from Sigma Aldrich and were used without further purification.

\section{Small batch nanoparticle synthesis at low concentrations, based on the study of Tang et al. ${ }^{14}$}

$\mathrm{Zn}\left(\mathrm{CH}_{3} \mathrm{CO}_{2}\right)_{2}(36 \mathrm{mg}, 1.5 \mathrm{mmol})$ was dissolved in ethanol $(20 \mathrm{ml})$ in an ultrasonic bath. $\mathrm{LiOH}(37 \mathrm{mg}, 0.2 \mathrm{mmol})$ was also ultrasonically dissolved in ethanol $(20 \mathrm{ml})$. Then, both solutions were mixed together and stirred. The synthesis was carried out under three different conditions: firstly in a lid-covered flask, secondly in an open flask (which allowed for air exchange) and thirdly in a flask flooded with nitrogen.

\section{Air bubble-assisted large batch nanoparticle synthesis at high concentrations}

In a typical synthesis, $\mathrm{Zn}\left(\mathrm{CH}_{3} \mathrm{CO}_{2}\right)_{2} \cdot 2 \mathrm{H}_{2} \mathrm{O}(8.13 \mathrm{~g}, 37 \mathrm{mmol})$ was dissolved in ethanol $(700 \mathrm{ml})$ with the help of continuous sonication using a Branson Sonifier II Model 450 for $15 \mathrm{~min}$ in an ice water bath. Also $\mathrm{KOH}(8.31 \mathrm{~g}, 148 \mathrm{mmol})$ was dissolved in ethanol $(280 \mathrm{ml})$ in an ultrasonic bath. After combining both solutions, compressed air was continuously bubbled into the stirred reaction batch at a selected flow rate. The compressed air was introduced into the reaction vessel via a glass frit with holes of a diameter of $200 \mu \mathrm{m}$. The reaction was performed for $6 \mathrm{~h}$. For testing the upscalability potential of the synthesis, the reaction was carried out with the same ratios of the precursors and the solvent as well as compressed air inlet but with a total reaction volume of 61 .

To examine the solubility of air in the reaction batch, the synthesis was furthermore executed with a small reaction volume of $50 \mathrm{ml}$ in a $1.5 \mathrm{l}$ high-pressure reactor at a normal pressure of 7 bar.

\section{Characterization}

Absorbance and luminescence of the particles were examined using a TECAN Multimode-Microplate-Reader Infinite ${ }^{\circledR}$ M1000 PRO in 96-well plates, giving evidence for the formation of nanoparticles. X-ray diffraction was carried out using a PANalytical Empyrean Series 2 employing $\mathrm{Cu} \mathrm{K}_{\alpha}$ radiation. The crystallite size of the nanoparticles was determined from the X-ray diffractograms, based on Scherrer's formula for the peaks at 47.5 and $56.5^{\circ}$ theta (by taking the average of the sum of these two peaks). To account for instrumental and angular broadening, $\mathrm{a} \mathrm{LaB}_{6}$ standard was measured as reference. By doing so, the peak broadening contribution from the instrument can be determined at the angles of interest and taken into account for the peak width at half maximum of the samples of interest. The shape and the size of the particles were studied using a transmission electron microscope FEI Titan operating at $300 \mathrm{keV}$. To quantitatively obtain the mean particle size and the size distribution of the synthesized $\mathrm{ZnO}$ nanoparticles, the size for 60 particles for each sample from TEM images was determined. This was done by fitting round circles around the lattice fringes of the nanoparticles and measuring their diameter.

The reaction yields from the particle syntheses were determined via centrifugation of $5 \mathrm{ml}$ of the reaction batch, decantation, drying and weighing of the obtained particle pellets.

\section{Results and discussion}

Our research was initially spiked by the finding that the method of $\mathrm{ZnO}$ nanoparticle synthesis, related to the approach of Tang et al., ${ }^{14}$ yielded very different results, depending on the accessibility of air during the synthesis. Therefore, we initially focused on the influence of the surrounding atmosphere on the synthesis result by comparing the reaction in a closed flask versus an opened flask which allowed air circulation, and a nitrogen flooded flask. The reactions were carried out using small volumes of ethanol $(40 \mathrm{ml})$ and low concentrated $\mathrm{Zn}\left(\mathrm{CH}_{3} \mathrm{CO}_{2}\right)_{2}$ and LiOH. After 4 hours of reaction, the turbidity described by Tang et al., ${ }^{14}$ indicating particle growth, was only observed in the case of air circulation. Fig. 1 shows the photoluminescence (PL) (Fig. 1a) and absorbance (Fig. 1b) spectra of the three differently treated samples. Both spectra reaffirm the visual impression, as only the sample reacted under air circulation shows a significant PL and absorbance for the wavelength ranges that are expected from what has been described in the literature for $\mathrm{ZnO}$ nanoparticles. ${ }^{10,14}$ While a slight PL of the other samples (closed flask, respectively nitrogen flooded) also indicates a minor particle formation, the yields of these reactions are very small and therefore not of interest for upscaling intentions. The slightly higher PL intensity of the nitrogen flooded in comparison to the closed reaction batch can be explained by the enhanced formation of oxygen vacancies in a nitrogen atmosphere. ${ }^{8}$ Negative absorbance values in the 
a)

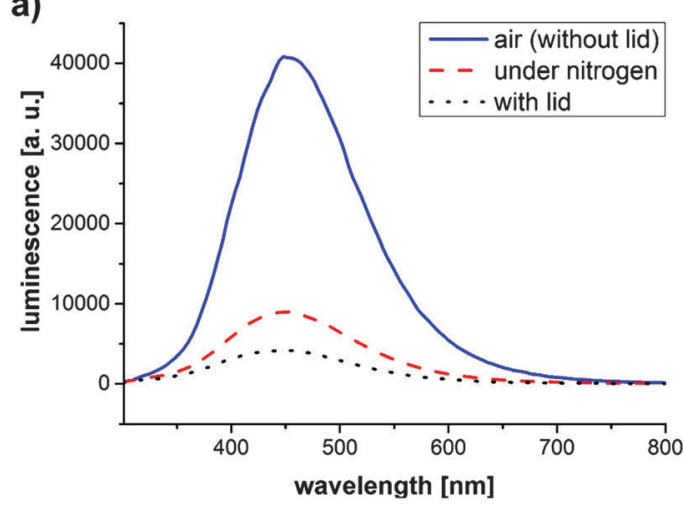

b)

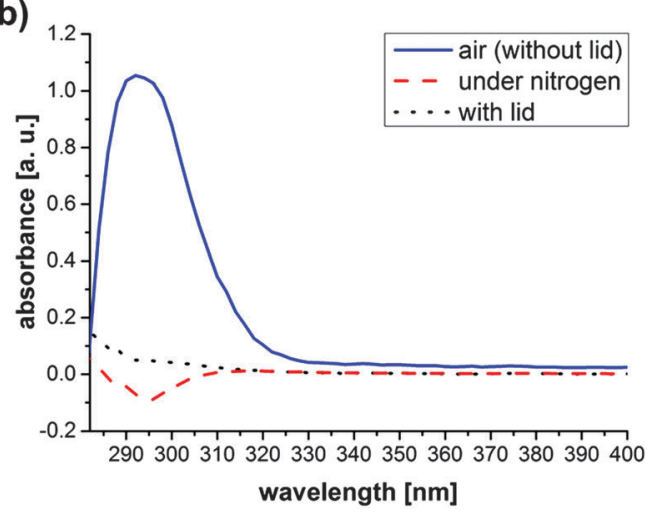

Fig. 1 (a) Luminescence and (b) absorbance spectra of $\mathrm{ZnO}$ nanoparticles after $4 \mathrm{~h}$ of reaction time, synthesized in flasks closed with a lid (dotted line), without a lid allowing air circulation (solid line) or under a nitrogen atmosphere (dashed line). As precursors, low $\mathrm{Concentrated} \mathrm{Zn}\left(\mathrm{CH}_{3} \mathrm{CO}_{2}\right)_{2}$ and $\mathrm{LiOH}$ in ethanol were chosen.

case of the nitrogen atmosphere are due to the measurement method in well plates. Small variations of the measured sample volumes result in less absorbance and due to the subtraction of ethanol as reference negative values can be obtained.

Therefore it can be concluded that oxygen is the driving force for an enhanced particle formation. The atmospheric oxygen dissolves at the air-liquid interface in the ethanol solution. According to the hypothesis introduced by Spanhel and Anderson, ${ }^{20}$ zinc oxide nanoparticles are obtained by a rapid formation and combination of molecular building blocks ((1) and (2)), which is followed by particle growth (3):

$$
\begin{gathered}
m \mathrm{Zn}^{2+}+n \mathrm{O}^{2-} \Rightarrow(\mathrm{ZnO})_{m} \\
(\mathrm{ZnO})_{m}+(\mathrm{ZnO})_{m} \Rightarrow(\mathrm{ZnO})_{2 m} \\
\mathrm{Zn}^{2+}+\mathrm{O}^{2-}+(\mathrm{ZnO})_{m} \Rightarrow(\mathrm{ZnO})_{m+1}
\end{gathered}
$$

These simplified reaction models suggest that the presence of free oxygen promotes the formation and growth of nanoparticles. Therefore, with a more pronounced presence of oxygen in solution, more zinc oxide primary particles are formed (also faster). To verify this hypothesis, we carried out the synthesis in a reaction vessel under standard pressure and under an air pressure of 7 bars. With higher air pressure the partial pressure of the aerial oxygen is higher as well and more oxygen dissolves at the liquid-air interface. With this pressure variation experiment, it turned out that our assumption could be confirmed, as the reaction yield of grown $\mathrm{ZnO}$ nanoparticles was increased by approximately $4 \%$ with elevated air pressure. It can therefore be concluded that high amounts of oxygen promote the $\mathrm{ZnO}$ nanoparticle formation. However, highpressure reactions are often not desired due to the challenges that are faced when going to larger scales. Possibly, the use of oxidants could be an alternative, however, the addition of further chemicals might negatively influence the reaction by changing the $\mathrm{pH}$ or generating undesired side products. Thus, with respect to these considerations, for upscaling, a new approach has to be sought to provide enlarged reaction volumes with sufficient oxygen. The reason is that as soon as the synthesis batches increase in volume, the ratio of the air-liquid interface to the reaction volume decreases as depicted in Fig. 2. Hence, the oxygen that dissolves at the interface is not sufficient for promoting the reaction effectively. To circumvent this bottleneck, the inlet of air bubbles was tested as an efficient tool to increase the air-liquid interface. By variation of the flow rate of compressed air, forming bubbles in the batch reaction vessel when flowing through a glass frit with $200 \mu \mathrm{m}$ pores,

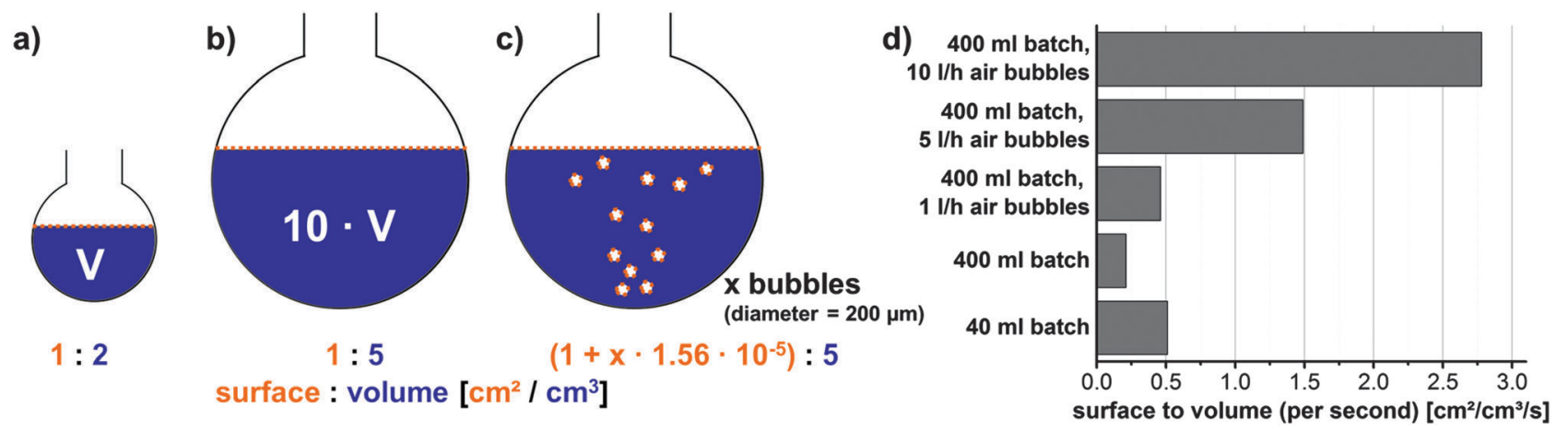

Fig. 2 Scheme to demonstrate changes in the surface to volume ratio when going from (a) a small reaction batch (40 $\mathrm{ml}$ in a $50 \mathrm{ml} f$ lask) to (b) a 10 times larger reaction batch $(400 \mathrm{ml}$ batch in a $500 \mathrm{ml}$ flask). (c) Shows the way to increase the surface to volume ratio by introducing air bubbles. (d) Depicts the calculated surface to volume ratios (per second) that are obtained for the $40 \mathrm{ml}$ and $400 \mathrm{ml}$ reaction batch without any additional air inlet and for the $400 \mathrm{ml}$ batch when compressed air at 1,5 and $10 \mathrm{l} \mathrm{h}^{-1}$ is added. 

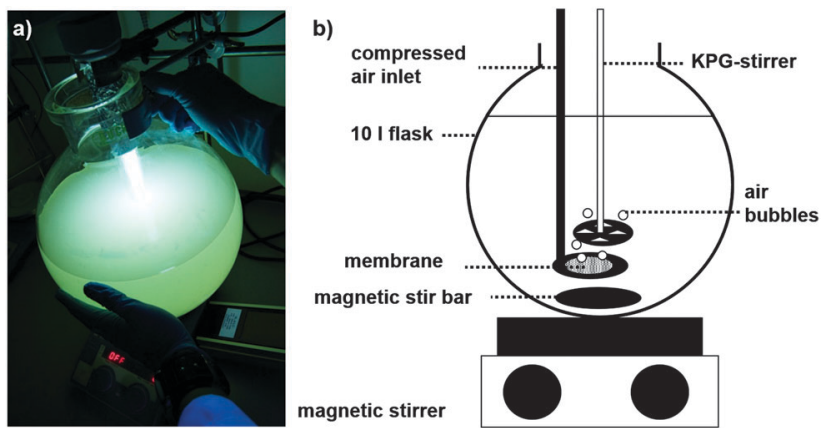

Fig. 3 (a) Photograph of a 6 I reaction batch under UV-light excitation (300-400 nm, $15 \mathrm{~W}$ ) and (b) scheme of a 10 I reaction set up.

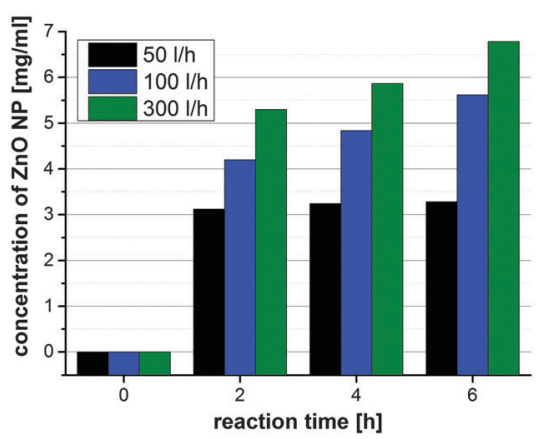

Fig. 4 Concentration of zinc oxide nanoparticles synthesized with 50, 100 and $300 \mathrm{l} \mathrm{h}^{-1}$ compressed air flow.

the ratio of air-liquid-surface to reaction-volume can be arbitrarily and finely manipulated and thus renders upscaling of the reaction possible. Fig. 3 depicts a photograph of a large scale reaction batch under UV-light excitation and the reaction set-up for large scale synthesis in a 101 reactor. Due to the air inlet, even a much higher surface to volume ratio compared to the small batch reaction can be achieved.

To further examine the influence of air bubbles on the reaction, syntheses at a one liter scale were carried out using
$\mathrm{KOH}$ and $\mathrm{Zn}\left(\mathrm{CH}_{3} \mathrm{CO}_{2}\right)_{2} \cdot 2 \mathrm{H}_{2} \mathrm{O}$ as inexpensive educts. In Fig. 4 the concentration of obtained nanoparticles as a function of the reaction time is depicted. By increasing the flow rate of compressed air from 50 to $300 \mathrm{l} \mathrm{h}^{-1}$, the particle concentration or reaction yield can be increased, as higher flow rates imply more bubbles and therefore a higher liquid-air interface, i.e. more oxygen is dissolved and hence more particles are formed. The examination of the obtained particle concentrations during the reaction raises the question if the yield increases due to the formation of new particles of the same size or if the particles just age and get larger. Looking at the PL (Fig. 5(a)), the maximum of the particle luminescence is found for all cases and at all points in time at $556 \mathrm{~nm}$. This proves that the particles always retain the same size as the PL would shift if their size was changed. ${ }^{10,13,14}$

Transmission electron microscopy images (Fig. 6) also confirm the same particle size for all samples: for the sample synthesized with $50 \mathrm{l} \mathrm{h}^{-1}$ air flow, the size was counted to be $6.8 \mathrm{~nm}$ with a standard deviation of $1.5 \mathrm{~nm}$; for $100 \mathrm{l} \mathrm{h}^{-1}$ the particles are $6.0 \mathrm{~nm}$ in size with a std. dev. of $0.9 \mathrm{~nm}$ and for $300 \mathrm{l} \mathrm{h}^{-1}$ the particles are sized $6.2 \mathrm{~nm}$ with a std. dev. of $1.2 \mathrm{~nm}$. A size of about $6 \mathrm{~nm}$ is also obtained by applying Scherrer's formula on the X-ray diffractograms of the samples (an exemplary diffractogram is shown in Fig. 7).

Upon correlating the PL of the samples with the particle concentration (Fig. 5(b)), it becomes evident that the PL intensity per $\mathrm{mg}$ of particles is the same for the samples with 50 and $100 \mathrm{l} \mathrm{h}^{-1}$ air flow and does only decrease slightly during the reaction time while a flow rate of $300 \mathrm{l} \mathrm{h}^{-1}$ results in lower PL intensities per $\mathrm{mg}$ of particles.

This indicates that in the case of a flow rate of $100 \mathrm{lh}^{-1}$ the particle yield can be significantly increased without negative effects on the PL intensity of the sample while if the flow rate is chosen too high, the gain of particle yield is on the cost of the luminescence intensity of the sample. An explanation for this phenomenon might be that on the one hand, oxygen promotes the particle formation but on the other hand, the presence of a)

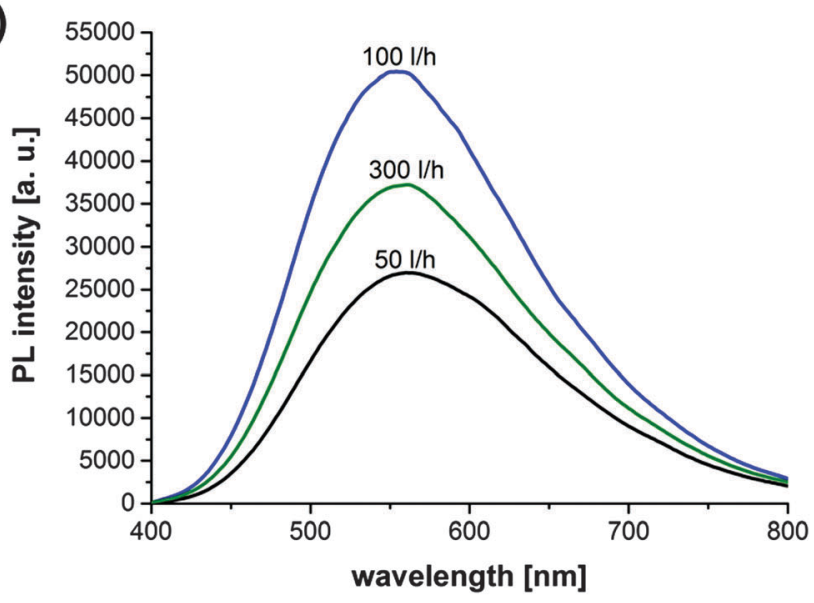

b)

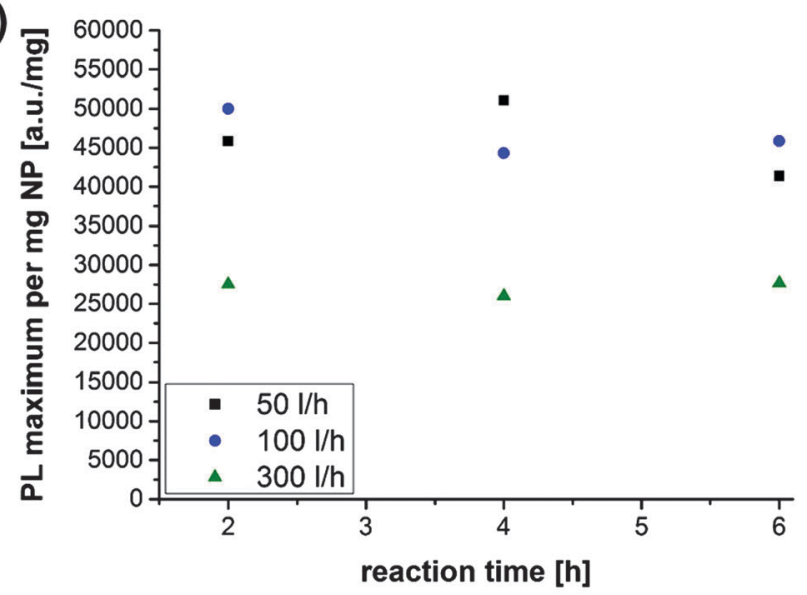

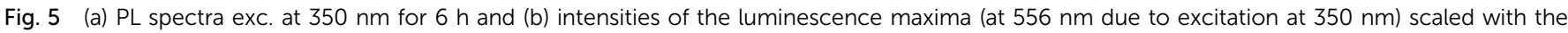

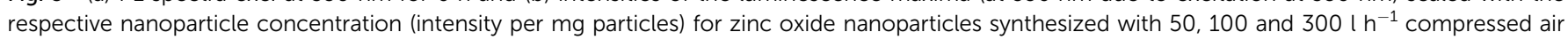
flow. 

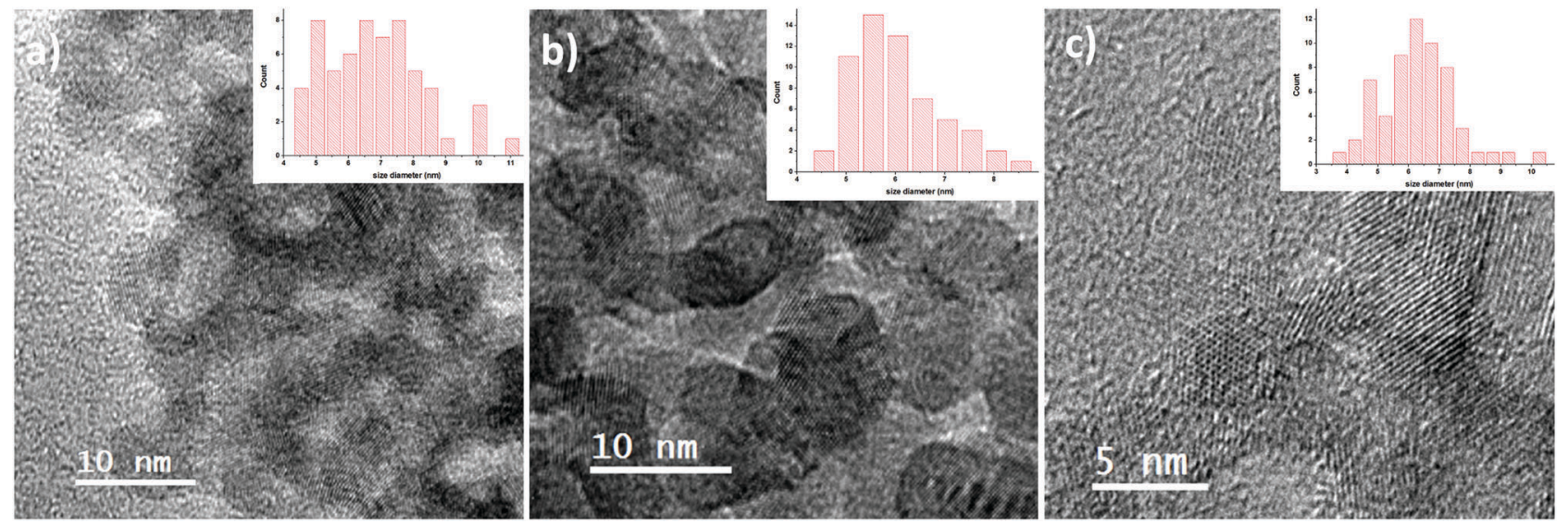

Fig. 6 Transmission electron microscopy images of $\mathrm{ZnO}$ nanoparticles after $6 \mathrm{~h}$ of reaction with an air flow of (a) $50 \mathrm{l} \mathrm{h}{ }^{-1}$, (b) $100 \mathrm{l} \mathrm{h}{ }^{-1}$, and (c) $300 \mathrm{l} \mathrm{h}{ }^{-1}$. (a) and (b) Were prepared on holey-carbon/copper TEM grids, and $\mathrm{ZnO}$ nanoparticles showing the hexagonal crystal lattice in (c) are supported by ultrathin carbon film. The insets show the size distribution, obtained from counting 60 particles.

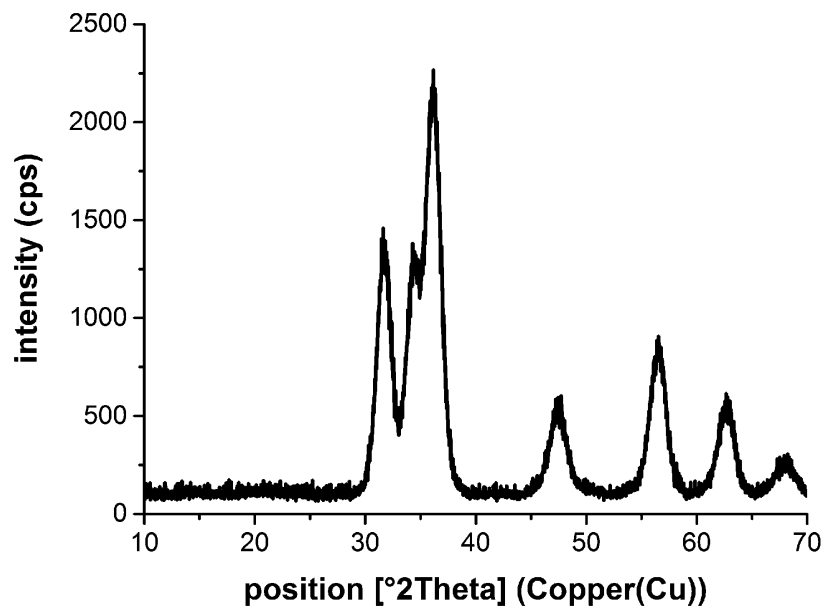

Fig. 7 Powder X-ray diffraction (XRD) patterns of zinc oxide nanoparticles (synthesized with $100 \mathrm{l} \mathrm{h}^{-1}$ compressed air inlet, after $6 \mathrm{~h}$ of reaction).

too much oxygen has a negative effect on the PL intensity. This is obvious as the luminescence is correlated with the oxygen defects of the $\mathrm{ZnO}$ crystals and if too much oxygen is present in the reaction solution, less oxygen vacancies are formed. Therefore, a flow rate of $100 \mathrm{l} \mathrm{h}^{-1}$ of compressed air is found to be the optimal setting to increase the yield of a 1 liter reaction batch without influencing the PL properties of the particles negatively.

\section{Conclusions}

In this work, it was demonstrated that the formation of zinc oxide nanoparticles is promoted by dissolved oxygen in the reaction solution. The upscaling of the reaction can be easily carried out by adding bubbles of compressed air to the larger batch synthesis vessel. By careful selection of the flow rate, the luminescence intensity of the zinc oxide nanoparticles can be maintained and the yield of the particles can be significantly increased. Thus, a facile and inexpensive method for the upscaling of luminescent zinc oxide nanoparticles was successfully developed.

\section{Acknowledgements}

This project has received funding from the European Union's Horizon 2020 research, an innovation programme under grant agreement No. 645993. We thank Rainer Jahn (Fraunhofer ISC, Wuerzburg, Germany) for the reproduction of the synthesis and the XRD measurements.

\section{Notes and references}

1 C. Klingshirn, Phys. Status Solidi B, 2007, 244, 3027-3073.

2 J. H. Li, D. Z. Shen, J. Y. Zhang, D. X. Zhao, B. S. Li, Y. M. Lu, Y. C. Liu and X. W. Fan, J. Lumin., 2007, 122, 352-354.

3 S. K. Arya, S. Saha, J. E. Ramirez-Vick, V. Gupta, S. Bhansali and S. P. Singh, Anal. Chim. Acta, 2012, 737, 1-21.

4 H.-M. Xiong, Y. Xu, Q.-G. Ren and Y.-Y. Xia, J. Am. Chem. Soc., 2008, 130, 7522-7523.

5 A. Janotti and Ch. G. Van de Walle, Rep. Prog. Phys., 2009, 72, 126501-126530.

6 A. van Dijken, E. A. Meulenkamp, D. Vanmaekelbergh and A. Meijerink, J. Lumin., 2000, 87-89, 454-456.

7 L. Spanhel, J. Sol-Gel Sci. Technol., 2006, 39, 7-24.

8 A. Asok, M. N. Ghandi and A. R. Kulkarni, Nanoscale, 2012, 4, 4943-4946.

9 K. Vanheusden, C. H. Seager, W. L. Warren, D. R. Tallant and J. A. Voigt, Appl. Phys. Lett., 1996, 68, 403-405.

10 Y. Lv, W. Xiao, W. Li, J. Xue and J. Ding, Nanotechnology, 2013, 24, 175702-175712.

11 A. van Dijken, E. A. Meulenkamp, D. Vanmaekelbergh and A. Meijerink, J. Lumin., 2000, 90, 123-128.

12 K.-F. Lin, H.-M. Cheng, H.-Ch. Hsu, L.-J. Lin and W.-F. Hsieh, Chem. Phys. Lett., 2005, 409, 208-211.

$13 \mathrm{X} . \mathrm{Xu}, \mathrm{Ch} . \mathrm{Xu}, \mathrm{X}$. Wang, Y. Lin, J. Dai and J. Hub, CrystEngComm, 2013, 15, 977-981.

14 X. Tang, E. S. Guang Choo, L. Li, J. Ding and J. Xue, Chem. Mater., 2010, 22, 3383-3388. 
15 S. T. Tan, X. W. Sun, J. L. Zhao, S. Iwan, Z. H. Cen, T. P. Chen, J. D. Ye, G. Q. Lo, D. L. Kwong and K. L. Teo, Appl. Phys. Lett., 2008, 93, 013506.

16 L. Selagard, V. Khranovskyy, F. Söderling, C. Vahlberg, M. Ahren, P.-O. Käll, R. Yakimova and K. Uvdal, ACS Appl. Mater. Interfaces, 2010, 2, 2128-2135.

17 S. C. Zhang and X. G. Li, Colloids Surf., A, 2003, 226, 35-44.

18 Y. Wang, C. Zhang, S. Bi and G. Luo, Powder Technol., 2010, 202, 130-136.

19 M. Vafaee and M. Sasani Ghamsari, Mater. Lett., 2007, 61, 3265-3268.

20 L. Spanhel and M. A. Anderson, J. Am. Chem. Soc., 1991, 113, 2826-2833.

21 C.-H. Lu and C.-H. Yeh, Ceram. Int., 2000, 26, 351-357.

22 B. Baruwati, D. K. Kumar and S. V. Manorama, Sens. Actuators, B, 2006, 119, 676-682.

23 Y. Ding, P. X. Gao and Z. L. Wang, J. Am. Chem. Soc., 2004, 126, 2066-2072.
24 S. K. Mohanta, D. C. Kim, H. K. Cho, S. J. Chua and S. Tripathy, J. Cryst. Growth, 2008, 310, 3208-3213.

25 J. H. Choi, H. Tabata and T. Kawai, J. Cryst. Growth, 2001, 226, 493-500.

26 X. Q. Wei, Z. Zhang, Y. X. Yu and B. Y. Man, Opt. Laser Technol., 2009, 41, 530-534.

27 M. L. Kahn, A. Glaria, C. Pages, M. Monge, L. Saint Macary, A. Maisonnat and B. Chaudret, J. Mater. Chem., 2009, 19, 4044-4060.

28 S. Kumar and P. D. Sahare, Opt. Commun., 2012, 285, 5210-5216.

29 Z. Chen, X. X. Li, G. Du, N. Chen and A. Y. M. Suen, J. Lumin., 2011, 131, 2072-2077.

30 H.-M. Xiong, Adv. Mater., 2013, 25, 5329-5335.

31 E. A. Meulenkamp, J. Phys. Chem. B, 1998, 102, 5566-5572.

32 R. D. Yang, S. Tripathy, Y. Li and H.-J. Sue, Chem. Phys. Lett., 2005, 411, 150-154.

33 K. Rekha, M. Nirmala, M. G. Nair and A. Anukaliani, Physica B, 2010, 405, 3180-3185. 